\title{
Galvanic replacement induced electromotive force to propel Janus micromotors
}

Cite as: J. Chem. Phys. 150, 144902 (2019); https://doi.org/10.1063/1.5085838

Submitted: 15 December 2018 . Accepted: 11 March 2019 . Published Online: 08 April 2019

(D) Julio Bastos-Arrieta, (D) Christoph Bauer, (D) Alexander Eychmüller, et al.

\section{COLLECTIONS}

Paper published as part of the special topic on Chemical Physics of Active Matter
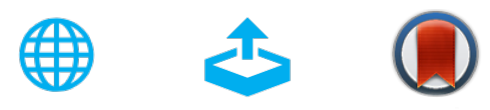

\section{ARTICLES YOU MAY BE INTERESTED IN}

Theory of light-activated catalytic Janus particles

The Journal of Chemical Physics 150, 114903 (2019); https://doi.org/10.1063/1.5080967

Which interactions dominate in active colloids?

The Journal of Chemical Physics 150, 061102 (2019); https://doi.org/10.1063/1.5082284

Light-controlled assembly of active colloidal molecules

The Journal of Chemical Physics 150, 094905 (2019); https://doi.org/10.1063/1.5079861

\section{Challenge us.}

What are your needs for periodic signal detection?

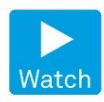

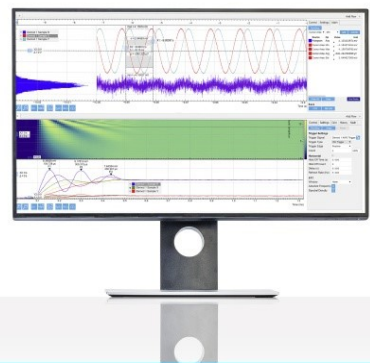

- Zurich

Instruments 


\title{
Galvanic replacement induced electromotive force to propel Janus micromotors
}

\author{
Cite as: J. Chem. Phys. 150, 144902 (2019); doi: 10.1063/1.5085838 \\ Submitted: 15 December 2018 - Accepted: 11 March 2019 • \\ Published Online: 8 April 2019
}

Julio Bastos-Arrieta, (D) Christoph Bauer, (D) Alexander Eychmüller, (D) and Juliane Simmchen ${ }^{\text {a) }}$

\author{
AFFILIATIONS \\ Physical Chemistry TU Dresden, Zellescher Weg 19, 01062 Dresden, Germany
}

Note: This article is part of the Special Topic "Chemical Physics of Active Matter" in J. Chem. Phys.

a) Author to whom correspondence should be addressed: juliane.simmchen@tu-dresden.de

\begin{abstract}
Electrochemistry is a highly versatile part of chemical research which is involved in many of the processes in the field of micromotion. Its input has been crucial from the synthesis of microstructures to the explanation of phoretic mechanisms. However, using electrochemical effects to propel artificial micromotors is still to be achieved. Here, we show that the forces generated by electrochemical reactions can not only create active motion, but they are also strong enough to overcome the adhesion to the substrate, caused by the increased ionic strength of the solutions containing the ions of more noble metals themselves. The galvanic replacement of copper by platinum ions is a spontaneous process, which not only provides a sufficiently strong electromotive force to propel the Janus structures but also results in asymmetric Pt-hatted structures, which can be further used as catalytic micromotors.
\end{abstract}

Published under license by AIP Publishing. https://doi.org/10.1063/1.5085838

\section{INTRODUCTION}

Electrochemical processes can be used to synthesize materials, characterize their electrical properties, and produce a usable electric potential. Since the early years of artificial motion on the microscale, plenty of electrochemical fabrication methods have been deployed in order to produce a variety of micromotors. ${ }^{1}$ Starting from the bimetallic rods that have marked the initial electrophoretic swimmers, ${ }^{2,3}$ other asymmetric structures evolved which were often produced by bipolar electrochemical deposition ${ }^{4-6}$ to a more simple and straightforward approach to produce tubular motors. ${ }^{7,8}$ From an analytical point of view, electrochemical techniques are widely used to characterize employed materials and material combinations. One example is results from cyclic voltammetry or Tafel plots that are commonly discussed in related publications. Nearly any propulsion mechanism, besides bubble propulsion, ${ }^{9}$ is associated with electrochemical reactions ${ }^{10}$ or conditions. ${ }^{11,12}$ Even for neutral diffusiophoresis, the one phoretic mechanism that was believed not to be influenced by charge distribution, several observations indicate that this initial assumption must be corrected. ${ }^{13-15}$ On the other hand, the dielectrophoretic interactions in electric fields have also proven to be a sophisticated way to successfully propel and assemble particles. ${ }^{16,17}$ Looking at the applications of micromotors, electrochemistry plays a role, with the electrochemical detection of biosensors being a well-established procedure. $^{18-21}$

However, despite these frequent links between electrochemistry and micromotion, the use of the electromotive force (EMF) as a propulsive mechanism needs further research. EMF refers to the maximum potential difference between two electrodes of a cell. However, since this potential is only related to the tendency of an element to gain or release electrons, no applied current is required, and the work generated from this reaction is directly suitable to propel micromotors. To the best of our knowledge, this has not been shown yet.

In nanotechnology, galvanic replacement reactions are frequently used for the fabrication of hollow nanostructures and microstructures, for the inexpensive production of catalysts ${ }^{22}$ or for microscale alloying of different materials, obtaining tunable compositions, porosity, and shape. ${ }^{23}$ The galvanic replacement reactions are driven by the difference in the standard reduction potential between the solid sacrificial metal with a noble metal ion in the solution. ${ }^{24}$ Noble metal structures obtained via galvanic replacement are especially attractive for catalytic applications due to their larger reactive surface area, owing to the production of mostly 
hollow or porous surfaces and their much less expensive production route. $^{25}$

In the first part of this work, we take advantage of the high tendency of noble metal ion solutions, such as $\left[\mathrm{PtCl}_{6}\right]^{2-}$, to galvanically replace the sacrificial copper hemisphere of Janus particles. This chemical reaction creates an EMF, strong enough to enable the auto phoretic motion of Janus particles, despite the fact that no traditional fuel is present. In the second part, the suitability of galvanic replacement as an inexpensive strategy for the preparation of active galvanic Pt capped microswimmers is demonstrated.

\section{RESULTS AND DISCUSSION}

\section{Electromotive force to propel Janus particles}

Going back to the early work of Nernst and Faraday, we can define our Janus particles (see Experimental section for details) as an electrochemical cell, consisting of a $\mathrm{Cu}$ anode in a Pt-ion containing solution. After completion of the exchange, a double layer is built up but no further thermodynamically favored process is ongoing in the system.

Therein, the following half-cell reactions can be formulated, with the positive potential indicating a spontaneous reaction

$$
\begin{array}{rll}
\text { Anode : } & 2 \mathrm{Cu}_{(s)} \rightarrow 2 \mathrm{Cu}^{2+}+4 \mathrm{e}^{-} & \boldsymbol{E}_{\mathrm{Cu}^{2+} / \mathrm{Cu}}^{0}=0.34 \mathrm{~V}, \\
\text { Cathode : } & \operatorname{PtCl}_{6(a q)}^{2-}+4 \mathrm{e}^{-} \rightarrow \mathrm{Pt}_{(s)}+6 \mathrm{Cl}^{-} & \boldsymbol{E}_{\mathrm{PtCl}_{6}{ }^{2-} / \mathrm{Pt}}=0.74 \mathrm{~V}^{25}, \\
\text { Combined : } & 2 \mathrm{Cu}_{(s)}+\mathrm{PtCl}_{(a q)}^{2-} \rightarrow \mathrm{Pt}_{(s)}+2 \mathrm{CuCl}_{2(a q)}+2 \mathrm{Cl}^{-} & \boldsymbol{E}^{0}=0.40 \mathrm{~V} .
\end{array}
$$

This galvanic approach for the production of Pt capped microswimmers represents a spontaneous, simple and inexpensive methodology for the production of noble metal capped microswimmers. The conditions depend on the difference of reduction potentials of the two species, as well as on the concentration of the noble metal ions. ${ }^{25}$ The different optical properties of the two metals, as well as the different stoichiometry, allow the screening of the process by optical microscopy besides the documentation of the EMF as a propulsion generator for the active motion. Consequently, we present the first approach to use the EMF as a driving force for micromotors, transforming $\mathrm{Cu} @ \mathrm{SiO}_{2}$ particles into catalytic platinum motors obtained by galvanic replacement ( $\mathrm{g} \mathrm{Pt} @ \mathrm{SiO}_{2}$ motors).

Furthermore, the obtained particles are found to be catalytically active when placed in hydrogen peroxide solution, propelling themselves, as the decomposition of $\mathrm{H}_{2} \mathrm{O}_{2}$ takes place only on the Pt surface cap obtained by the galvanic replacement, generating concentration gradients of the solute that drive the movement. ${ }^{26,}$

The as deposited $\mathrm{Cu} @ \mathrm{SiO}_{2}$ Janus particles present a smooth half coverage on one of the hemispheres. Despite the nanoscale roughness, these particles have a nearly spherical shape (as shown in Fig. 1). After the addition of $\mathrm{H}_{2} \mathrm{PtCl}_{6}$ (as a noble metal precursor), the visual impression of the particles changes strongly. The caps shrink in size and resemble hats instead of hemispheres. As expected from structures obtained by galvanic exchange, they present greater roughness, and further precipitates are observable.

This new morphology is due to the stoichiometric ratio $\mathrm{Cu} / \mathrm{Pt}$ [as shown in Eq. (3)] as well as the difference in atomic radii (1.28 for $\mathrm{Cu}$ and $1.39 \AA$ for $\mathrm{Pt}){ }^{28}$ Both effects contribute to the displacement of $\mathrm{Cu}$ atoms on the outermost layer of the Janus hemisphere through $\mathrm{PtCl}_{6}{ }^{2-}$, while only a fraction of the top layer of the $\mathrm{Cu}$ will be initially replaced by $\mathrm{Pt}$ atoms, leaving the inner $\mathrm{Cu}$ layers for further reactions.

The overall process leads to the increase in the roughness of the resulting Pt layers, but with a decrease in size when compared to the $\mathrm{Cu}$ template. This is visible in the loss of contrast optical images, resulting in "hatted particles." Also visible from the scanning electron microscopy (SEM) image is that the galvanic hat is not always permanently attached to the particle body; especially after the fast addition of the Pt-solution, many detached hats are observable. The change in the material of the metal cap/hat can be seen by energy dispersive x-ray (EDX) elemental mapping documented in Fig. 2. From both the convex and the concave part of the cap, the $\mathrm{Cu}$ is almost completely exchanged by Pt.

However, the galvanic replacement depends upon the presence of a high ionic strength-due to the required concentration of $\mathrm{Pt}$ ions-for which the $\mathrm{Cu}$ particles are initially attached to the bottom substrate [see Fig. 3 (Multimedia view)]. According to the Derjaguin-Landau-Verwey-Overbeek (DLVO) theory, the balance between the double layer interaction and van der Waals forces causes Janus particles to stick to the substrate walls, starting at ionic strengths just above $10^{-3} \mathrm{~mol} / \mathrm{l}$, leading to an inhibition of motion, random Brownian motion, and active motion. ${ }^{29}$ Here, we use $\mathrm{KCl}$ solutions with an ionic strength of $0.0015 \mathrm{~mol} / \mathrm{l}$ and find that the Brownian motion is nearly suppressed and inactive $\mathrm{Cu} @ \mathrm{SiO}_{2}$ particles stick to the substrate wall. Using a solution with a concentration of $\mathrm{H}_{2} \mathrm{PtCl}_{6}$ that gives a comparable ionic strength $(0.0006 \mathrm{~mol} / \mathrm{l})$, we observe that $\mathrm{Cu} @ \mathrm{SiO}_{2}$ particles initially stick to the substrate, but eventually start to move. Even after extended waiting time, in experiments using $\mathrm{KCl}$, a negligible amount of particles are able to detach and undergo Brownian motion for a short time, whereas after the addition of $\mathrm{H}_{2} \mathrm{PtCl}_{6}$, about $25 \%$ of the particles starts to move. The motion resembles Brownian motion in speed or is slightly higher, but we observe the position of the particles to be oriented with their symmetry axis about $0^{\circ}$ to the substrate, similarly to catalytic swimmers. ${ }^{30}$ This behaviour is due to the potential difference between the materials. Taking into account the ion concentrations obtained by inductively coupled plasma optical emission spectroscopy (ICP-OES) measurements in the Nernst equation, we can calculate the EMF and the Gibbs free energy $(\Delta \boldsymbol{G})$ for the actual process (see the following equations): 


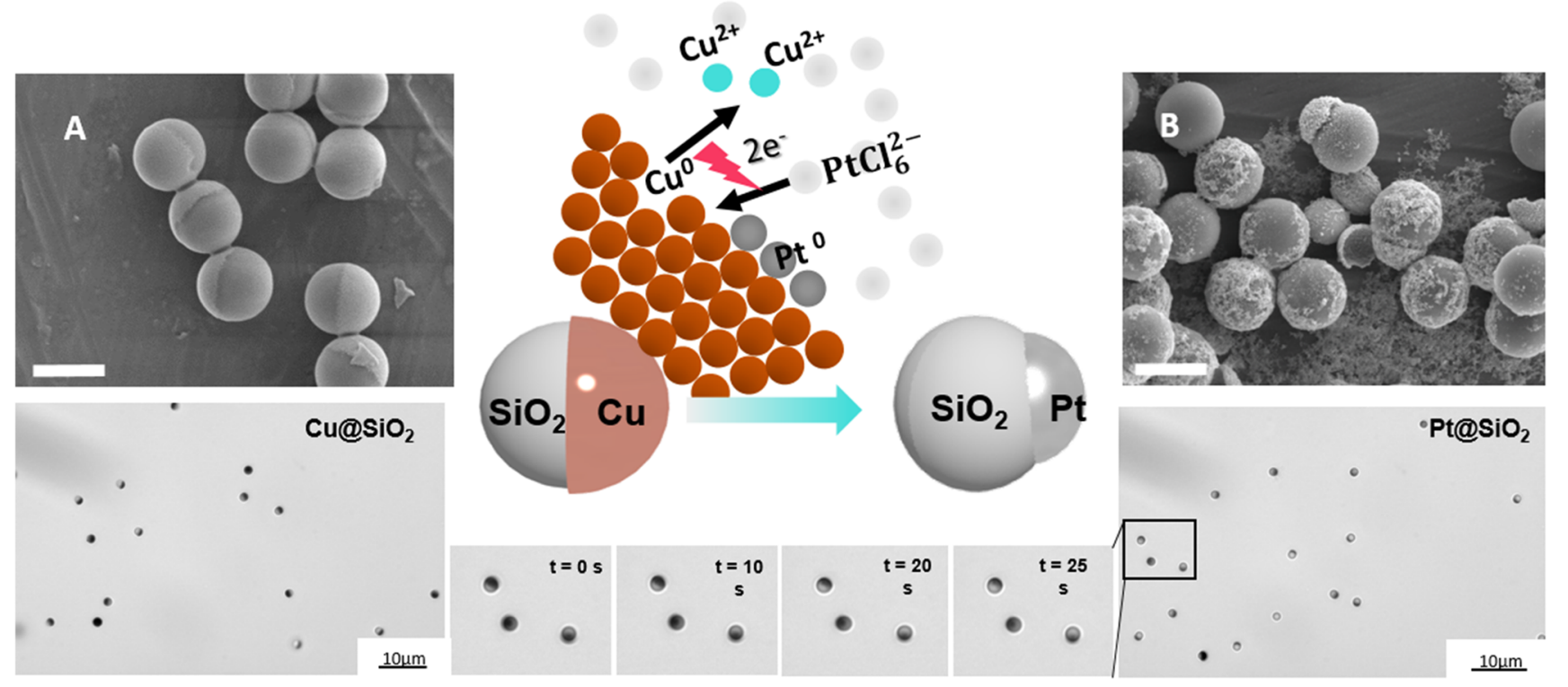

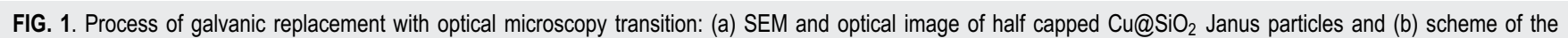
galvanic exchange inspired by Xia et al. ${ }^{25}$ and optical images documenting loss of intensity trough time. (c) SEM and optical image of ${ }_{g} \mathrm{Pt} @ \mathrm{SiO}_{2}$ after exchange. Scale bars correspond to $2 \mu \mathrm{m}$.

$$
\begin{aligned}
\text { EMF }_{\text {cell }} & =0.40-\frac{0.0591}{4} \log \frac{\left[\mathbf{P t C l}_{6}^{2-}\right]}{\left[\mathbf{C u}^{2+}\right]^{2}}, \\
E M F_{\text {cell }} & =0.40-\frac{0.0591}{4} \log \frac{\left[9.6 \times 10^{-5}\right]}{\left[7.8 \times 10^{-5}\right]^{2}}, \\
E M F_{\text {cell }} & =0.34 \mathrm{~V}, \\
\Delta G & =-4 \cdot 96500 \cdot E M F_{\text {cell }}, \\
\Delta G & =-1.31 \times 10^{5} \mathrm{~kJ} / \mathrm{mol}_{\mathrm{Cu}} .
\end{aligned}
$$

This potential characterizes the spontaneous reaction, and thus, the electrical energy released during the process, which can be used to generate work, equals the free energy of the system. The presence of $\mathrm{Cu}$ and $\mathrm{Pt}$ ions in the media leads to a decrease in the cell potential of $0.06 \mathrm{~V}$ in comparison with the standard potential for the galvanic replacement of $\mathrm{Cu}$ by $\mathrm{Pt}$, in addition to the significant attachment effect explained previously. Nevertheless, the Gibbs energy value obtained for the actual reaction conditions [Eq. (7)] was high enough for the eventual detachment from the substrate. This could
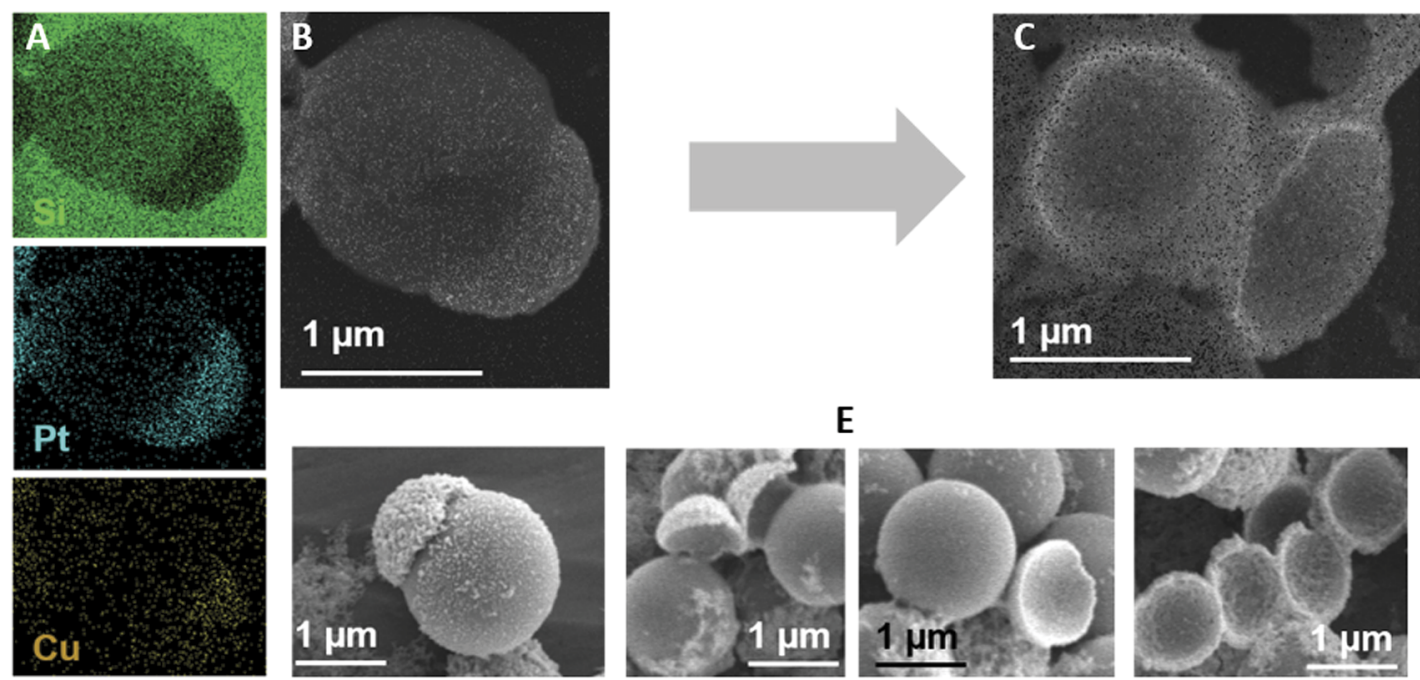

\section{$\mathrm{E}$}
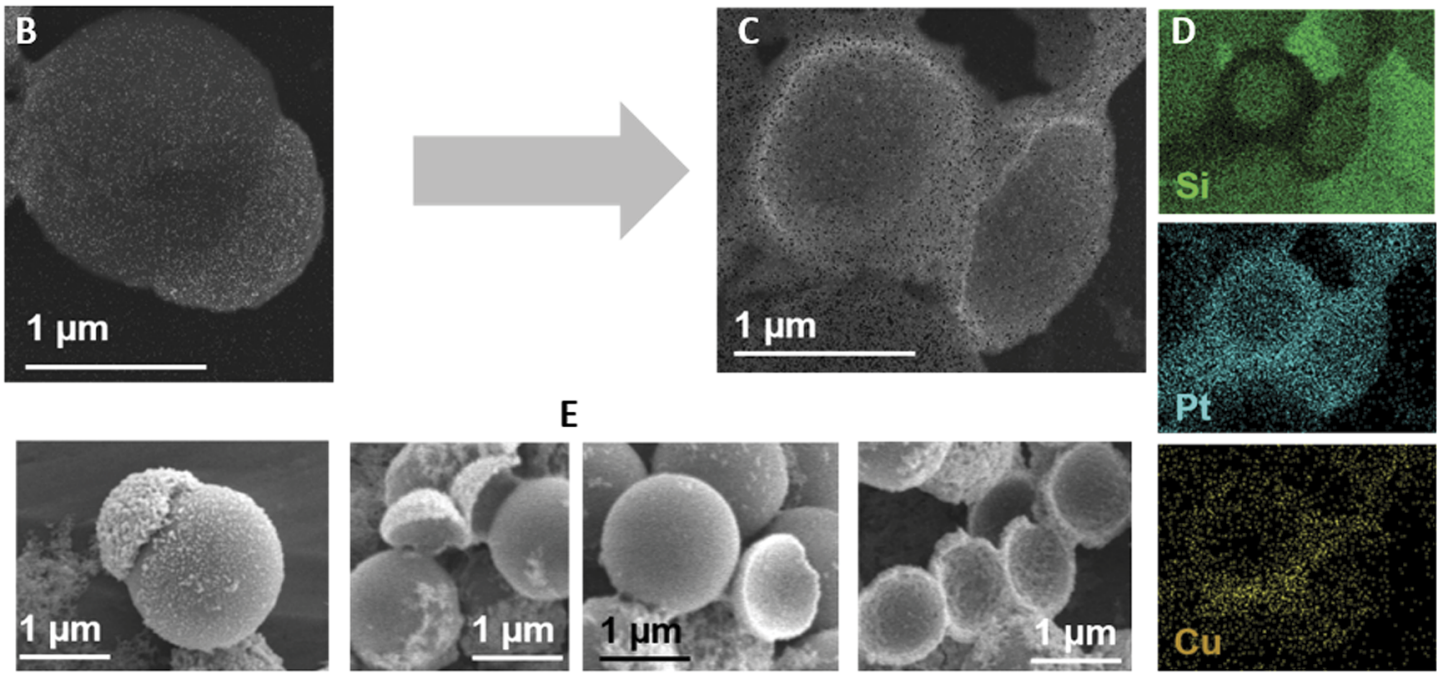

FIG. 2. EDX chemical mapping [(a)-(d)] and SEM of Pt@SiO $\mathrm{S}_{2}$ microswimmers with different morphologies obtained by the galvanic replacement reaction. 

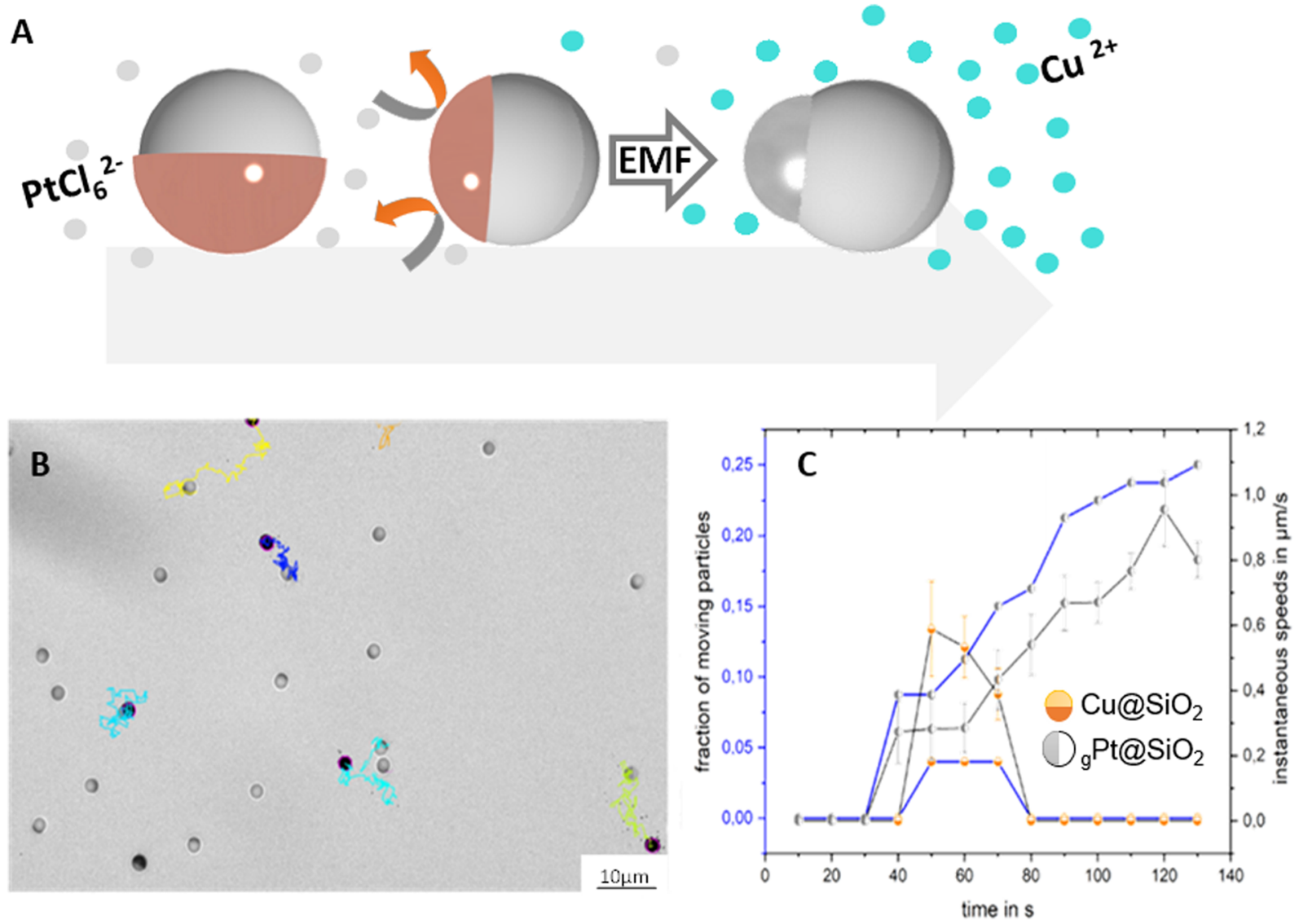

FIG. 3. (a) Scheme of the motion caused through the galvanic exchange and the EMF, (b) tracks end final positions of particles overcoming van der Waals adhesion on the substrate during the galvanic replacements, and (c) speeds and fraction of moving particles. Multimedia view: https://doi.org/10.1063/1.5085838.1

be explained to the predominant fact of the high difference between the standard reduction potential values of $\mathrm{Cu}$ and $\mathrm{Pt}[0.40 \mathrm{~V}$ as presented in Eq. (3)], which drives the high spontaneity of the process.

\section{Galvanic replacement as synthetic strategy}

Not only the process of replacing the copper by Pt in the metal cap gives rise to an EMF creating active propulsion, this approach can also be used in microtechnology. Also, the synthesis of $\mathrm{Pt}$ patches on the particles can be achieved using this electrochemical pathway. Depositing a layer of a non-noble metal and replacing it with $\mathrm{Pt}$ ions from a solution is more cost efficient in terms of machinery, but also material consumption. While several grams of Pt are needed to prepare an e-beam crucible or expensive sputter targets are used to cover the whole inner surface of the deposition machine, this material loss can be transferred to cheaper materials such as copper and only a small volume of Pt-salts can be employed to achieve catalytic patches.

However, the obtained structures are not exactly equivalent to their engineered counterparts. ${ }_{g} \mathrm{Pt} @ \mathrm{SiO}_{2}$ microswimmers obtained by the galvanic replacement with $\mathrm{Pt}$ starting from $\mathrm{Cu} @ \mathrm{SiO}_{2}$ Janus particles present different morphologies, which are difficult to obtain by common deposition methodologies. It can be differentiated between structures where the "hat" is completely attached to the particle [Fig. 4(a)], semi-detached as in Fig. 4(b), or fully detached, leading to passive $\mathrm{SiO}_{2}$ particles and actively swimming hats [see Fig. 4(c)].

The obtained microswimmers showed active motion due to the catalytic decomposition in dilute $\mathrm{H}_{2} \mathrm{O}_{2}$ solutions, as expected from catalytic Pt Janus microswimmers (see the summary table in the supplementary material). It is worth indicating that the loss of symmetry of the initial Janus particle as well as possible alloyed structures may lead to different swimming modes. In Fig. 4, we see three typical structures obtained by galvanic replacement of $\mathrm{Cu}$ by Pt. Representative tracked trajectories (for $30 \mathrm{~s}$ ) of ${ }_{g} \mathrm{Pt} @ \mathrm{SiO}_{2}$ particles with different morphologies are also presented in Fig. 4. The particles showed different motion with a maximum speed when the effective concentration of peroxide is $7 \% \mathrm{v} / \mathrm{v}$. Most similar to the initial particle geometry is the hatted particle, moving in irregular trajectories, with a maximum velocity of $4.1 \pm 0.8 \mu \mathrm{m} \mathrm{s}^{-1}$ [Fig. 4(a)]. The semi-detached morphology [Fig. 4(b)] showed a velocity of $2.7 \pm 0.9 \mu \mathrm{m} \mathrm{s}^{-1}$, often displaying very curvy trajectories or circling, which is due to the torque induced by the irregular particle 

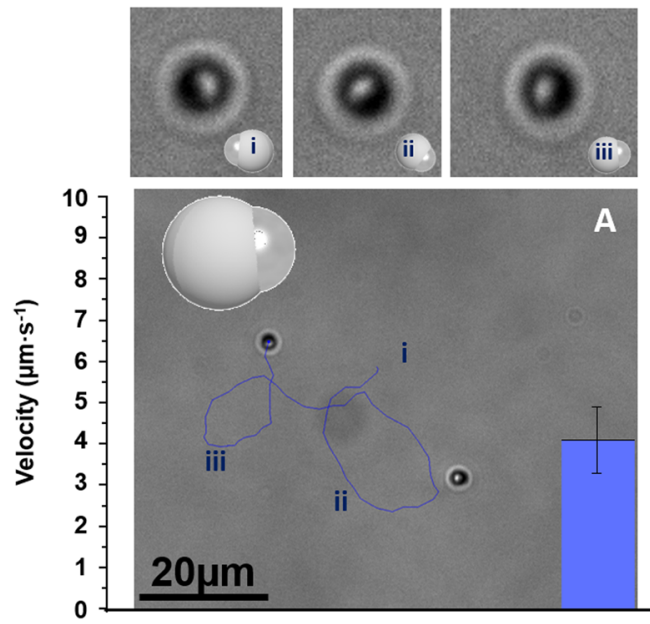
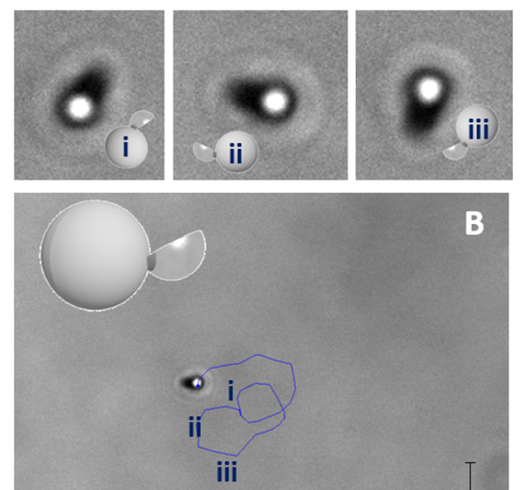

$\underline{20 \mu m}$

.
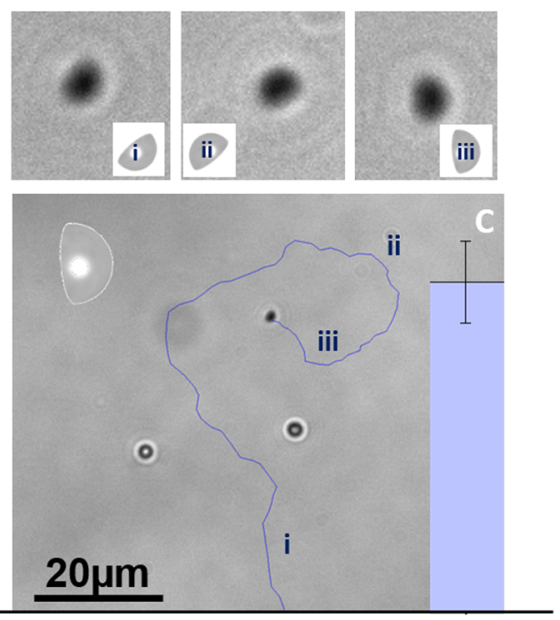

$\mathrm{H}_{2} \mathrm{O}_{2} 7 \% \mathrm{v} / \mathrm{v}$

FIG. 4. Upper row: Trajectories of the microswimmers after $25 \mathrm{~s}$ reaction in $7 \% \mathrm{H}_{2} \mathrm{O}_{2}$; lower row: swimming position of ${ }_{g} \mathrm{Pt@SiO} 2$ microswimmers (a), hatted particles (b), and semi-detached hatted $(\mathrm{c})$ motile caps swimming actively after loss of the microparticles. The velocity values $\left(\mu \mathrm{m} \mathrm{s}{ }^{-1}\right)$ are presented as an inset in each case.

attachment. The totally detached caps are also motile by themselves, as has previously been reported by Wang's group and others. ${ }^{31}$ These morphologies have the highest speed of $8 \pm 1 \mu \mathrm{m} \mathrm{s}^{-1}$, as this is the lightest microswimmer configuration.

\section{CONCLUSIONS}

Here, we presented a galvanic replacement strategy for the production of ${ }_{\mathrm{g}} \mathrm{Pt} @ \mathrm{SiO}_{2}$ Janus particles using $\mathrm{Cu} @ \mathrm{SiO}_{2}$ particles as templates. The synthetic electrochemical approach is based on the difference of reduction potential values of $\mathrm{Pt}$ and $\mathrm{Cu}$, which leads to a highly spontaneous process. Optical microscopy observation of the galvanic replacement of $\mathrm{Cu} @ \mathrm{SiO}_{2}$ to ${ }_{\mathrm{g}} \mathrm{Pt} @ \mathrm{SiO}_{2}$ Janus particles showed that the resulting EMF enables the particles to overcome the adhesion to the substrate at increased ionic strength values, resulting in a slow but steady motion. It is worth highlighting that the obtained ${ }_{\mathrm{g}} \mathrm{Pt} @ \mathrm{SiO}_{2}$ Janus particles have different morphologies compared to the initial copper structures; from SEM characterization, they resemble a hatted shape. This morphology is difficult to obtain by common platinum deposition methodologies. The differently prepared ${ }_{\mathrm{g}} \mathrm{Pt} @ \mathrm{SiO}_{2}$ microswimmers proved to be catalytically active and capable of motion when they were put in diluted hydrogen peroxide solutions.

\section{EXPERIMENTAL}

\section{Materials and reagents}

Chloroplatinic acid hydrate $\left(\mathrm{H}_{2} \mathrm{PtCl}_{6} \cdot \mathrm{H}_{2} \mathrm{O}\right)$ and $2 \mu \mathrm{m} \mathrm{SiO}$ particles were obtained from Sigma Co., Ltd. All other reagents including $\mathrm{H}_{2} \mathrm{O}_{2}$ were purchased from Sigma and were of analytical grade and used as received without further treatment. Milli- $Q$ water was used for preparing aqueous solutions.

\section{Synthesis of $\mathrm{Pt} / \mathrm{SiO}_{2}$ microswimmers via galvanic replacement}

First, monolayers of $2 \mu \mathrm{m} \mathrm{SiO}$ particles were prepared by Langmuir-Blodgett deposition, using a suspension of particles $5 \mathrm{wt}$ \% in ethanol/chloroform (1:4). Then, the particles were coated with a $\mathrm{Cu}$ layer (15 $\mathrm{nm}$ in thickness) by thermal deposition. Different morphologies of Pt microswimmers could be obtained by the galvanic replacement reaction. In order to obtain a higher amount of undetached ${ }_{g} \mathrm{Pt} @ \mathrm{SiO}_{2}$ microswimmers (and minimize possible detachment of $\mathrm{Pt}$ caps), the ratio between $\mathrm{Cu} @ \mathrm{SiO}_{2}$ (dispersed in Milli-Q water) and the Pt precursor was controlled. Therefore, $\mathrm{Cu}$ capped particles were immersed in $10 \mathrm{ml}$ of Milli-Q water and sonicated $5 \mathrm{~s}$. Then, $2 \mathrm{ml}$ of $\mathrm{H}_{2} \mathrm{PtCl}_{6} \cdot \mathrm{H}_{2} \mathrm{O} 0.6 \mathrm{mM}$ were added to $4 \mathrm{ml}$ of $\mathrm{Cu} @ \mathrm{SiO}_{2}$ particles suspension. After $10 \mathrm{~min}$ of the reaction, the exchanged ${ }_{g} \mathrm{Pt} @ \mathrm{SiO}_{2}$ particles were separated by centrifugation and rinsed three times with Milli-Q water.

\section{Microscopy analysis of $\mathrm{Cu} @ \mathrm{SiO}_{2}$ and $g \mathrm{Pt@SiO}$ particles}

Optical microscopy analysis of $\mathrm{Cu} @ \mathrm{SiO}_{2}$ and ${ }_{g} \mathrm{Pt} @ \mathrm{SiO}_{2}$ was performed in an optical microscope (Carl Zeiss Microscopy GmbH Germany) equipped with a Zeiss Colibri lamp. Glass slides were plasma treated in order to avoid the attachment of the particles to the slide. For the evaluation of Brownian motion of $\mathrm{Cu} @ \mathrm{SiO}_{2}$ particles, $10 \mu \mathrm{l}$ of particle suspension was placed on the glass slide. Image and video analyses were carried out using $25 \mathrm{~ms}$ of exposure time and a frame rate of $40 \mathrm{fps}$. Extended time experiments were carried out using $25 \mathrm{~ms}$ of exposure time, recording data for every second in cycles of $100 \mathrm{~s}$.

For the evaluation of Brownian motion of ${ }_{\mathrm{g}} \mathrm{Pt} @ \mathrm{SiO} 2$ microparticles, $10 \mu \mathrm{l}$ of $\mathrm{H}_{2} \mathrm{PtCl}_{6} \cdot \mathrm{H}_{2} \mathrm{O} 0.6 \mathrm{mM}$ solution were added to $10 \mu \mathrm{l}$ of $\mathrm{Cu} @ \mathrm{SiO}_{2}$ particle suspension. Data acquisition is the same as 
described for the previous case, in order to record in situ the galvanic replacement reaction for the synthesis of ${ }_{g} \mathrm{Pt} @ \mathrm{SiO}_{2}$ microparticles.

For determining the swimming behavior of $\mathrm{Pt} @ \mathrm{SiO}_{2}$ microswimmers, $5 \mu \mathrm{l}$ of ${ }_{g} \mathrm{Pt} @ \mathrm{SiO}_{2}$ particle suspension and $10 \mu \mathrm{l}$ of hydrogen peroxide solution of 10 vol. \% in water were used. The analysis of the recorded videos was carried out using the tracking tool from ImageJ software version 1.52i (National Institute of Health, USA). ${ }^{32}$

\section{Metal content analysis}

Inductively coupled plasma optical emission spectroscopy (ICP-OES) was carried out on a Perkin-Elmer Optima 7000 DV optical emission spectrometer for the determination of the metal content $(\mathrm{Cu}, \mathrm{Pt})$ during the different stages of the preparation of ${ }_{\mathrm{g}} \mathrm{Pt} @ \mathrm{SiO}_{2}$ microswimmers. Particles were separated from ICP samples by centrifugation. Dissolution was done in nitric acid.

\section{Electron microscopy characterization}

Scanning electron microscopy (SEM) characterization was performed on a Zeiss DSM 982 Gemini instrument. SEM-EDX measurements were performed using an SU8000 SE Microscope (Hitachi).

\section{SUPPLEMENTARY MATERIAL}

See supplementary material for additional information regarding metal content analysis, velocity comparison with other Pt cap catalytic microswimmers, zeta potential data, and further EDX characterization.

\section{ACKNOWLEDGMENTS}

The authors thank the SMWK Saxony for the TG70 grant BACMOT (Grant No. 100315856), and J.S. thanks the Volkswagen foundation for the Freigeist fellowship (Grant No. 91619). The ICP OES measurements of R. Schulze and the ZP measurements performed by S. Görke are greatly acknowledged.

The authors declare no conflicts of interest.

\section{REFERENCES}

${ }^{1}$ J. G. S. Moo, C. C. Mayorga-Martinez, H. Wang, B. Khezri, W. Z. Teo, and M. Pumera, Adv. Funct. Mater. 27 (2017)

${ }^{2}$ B. R. Martin, D. J. Dermody, B. D. Reiss, M. Fang, L. A. Lyon, M. J. Natan, and T. E. Mallouk, Adv. Mater. 11, 1021 (1999).
${ }^{3}$ W. F. Paxton, K. C. Kistler, C. C. Olmeda, A. Sen, S. K. St. Angelo, Y. Cao, T. E. Mallouk, P. E. Lammert, and V. H. Crespi, J. Am. Chem. Soc. 126, 13424 (2004). ${ }^{4}$ I. Malytska, C. Mézière, M. Kielar, L. Hirsch, G. Wantz, N. Avarvari, A. Kuhn, and L. Bouffier, J. Phys. Chem. C 121, 12921 (2017).

${ }^{5}$ N. Sojic, C. Warakulwit, J. Limtrakul, H. Li, O. Phuakkong, M. Sentic, A. Kuhn, V. Ravaine, and D. Zigah, Langmuir 32, 12995 (2016).

${ }^{6}$ Z. A. Fattah, L. Bouffier, and A. Kuhn, Appl. Mater. Today 9, 259 (2017).

${ }^{7}$ W. Gao, S. Sattayasamitsathit, J. Orozco, and J. Wang, J. Am. Chem. Soc. 133 11862 (2011).

${ }^{8}$ L. Wang, J. Chen, X. Feng, W. Zeng, R. Liu, X. L. Xiujing Lin, Y. Ma, and L. Wang, RSC Adv. 6, 65624 (2016).

${ }^{9}$ A. Klingner, I. S. M. Khalil, V. Magdanz, V. M. Fomin, O. G. Schmidt, and S. Misra, J. Phys. Chem. C 121, 14854 (2017).

${ }^{10}$ M. Kuron, P. Kreissl, and C. Holm, Acc. Chem. Res. 51, 2998 (2018).

${ }^{11}$ Y. Dou, C. A. Cartier, W. Fei, S. Pandey, S. Razavi, I. Kretzschmar, and K. J. M. Bishop, Langmuir 32, 13167 (2016).

${ }^{12}$ K. J. M. Bishop, A. M. Drews, C. A. Cartier, S. Pandey, and Y. Dou, Langmuir 34, 6315 (2018).

${ }^{13}$ J. Simmchen, V. Magdanz, S. Sanchez, S. Chokmaviroj, D. Ruiz-Molina, A. Baeza, and O. G. Schmidt, RSC Adv. 4 (2014).

${ }^{14} \mathrm{~A}$. Brown and W. Poon, Soft Matter 10, 4016 (2014).

${ }^{15}$ A. T. Brown, W. C. K. Poon, C. Holm, and J. de Graaf, Soft Matter 13, 1200 (2017).

${ }^{16}$ A. F. Demirörs and L. Alison, J. Phys. Chem. Lett. 9, 4437 (2018).

${ }^{17}$ A. F. Demirörs, M. T. Akan, E. Poloni, and A. R. Studart, Soft Matter 14, 4741 (2018).

${ }^{18}$ S. Campuzano, J. Orozco, D. Kagan, M. Guix, W. Gao, S. Sattayasamitsathit, J. C. Claussen, A. Merkoçi, and J. Wang, Nano Lett. 12, 396 (2012).

${ }^{19}$ J. Simmchen, A. Baeza, D. Ruiz, M. J. Esplandiu, and M. Vallet-Regí, Small 8, 2053 (2012)

${ }^{20}$ Y. Xie, S. Fu, J. Wu, J. Lei, and H. Ju, Biosens. Bioelectron. 87, 31 (2017).

${ }^{21}$ B. Jurado-Sánchez and A. Escarpa, Electroanalysis 29, 14 (2017).

${ }^{22}$ B. Cai, R. Hübner, K. Sasaki, Y. Zhang, D. Su, C. Ziegler, M. B. Vukmirovic, B. Rellinghaus, R. R. Adzic, and A. Eychmüller, Angew. Chem., Int. Ed. 57, 2963 (2018).

${ }^{23}$ B. D. Anderson and J. B. Tracy, Nanoscale 6, 12195 (2014).

${ }^{24}$ A. Ott, S. K. Bhargava, and A. P. O'Mullane, Surf. Sci. 606, L5 (2012).

${ }^{25}$ X. Xia, Y. Wang, A. Ruditskiy, and Y. Xia, Adv. Mater. 25, 6313 (2013).

${ }^{26}$ J. L. Moran and J. D. Posner, Annu. Rev. Fluid. Mech. 49, 511 (2017).

${ }^{27}$ S. Sanchez, L. Soler, and J. Katuri, Angew. Chem., Int. Ed. 54, 1414 (2015).

${ }^{28}$ A. Sarkar and A. Manthiram, J. Phys. Chem. C 114, 4725 (2010).

${ }^{29} \mathrm{~J}$. Katuri, Self-Propelled Janus Particles in Confined Spaces (Universität Stuttgart, Stuttgart, 2014).

${ }^{30}$ J. Simmchen, J. Katuri, W. E. Uspal, M. N. Popescu, M. Tasinkevych, and S. Sánchez, Nat. Commun. 7, 1 (2016).

${ }^{31}$ X. Ma, S. Jang, M. N. Popescu, W. E. Uspal, A. Miguel-López, K. Hahn, D. P. Kim, and S. Sánchez, ACS Nano 10, 8751 (2016).

${ }^{32} \mathrm{~J}$. Schindelin, I. Arganda-Carreras, E. Frise, V. Kaynig, M. Longair, T. Pietzsch, S. Preibisch, C. Rueden, S. Saalfeld, and B. Schmid, Nat. Methods 9, 676 (2012). 